\title{
MATHEMATICAL MODELS OF GEOMETRIC SIZES OF CEREAL CROPS' SEEDS AS DEPENDENT RANDOM VARIABLES
}

\author{
Roman KUZMINSKYI*, Stefan KOVALISHYN, Yurij KOVALCHYK, Roman SHEREMETA \\ Lviv National Agrarian University, Dubliany, Zhovkva district, Ukraine
}

\begin{abstract}
Dimensions of 100 randomly selected wheat seeds of the Smuglyanka variety, rye seeds of the Puhovchanka variety and barley seeds of the Pejas variety were determined by measuring their length $(l)$, width $(b)$ and thickness $(h)$. Results of the measurements were processed by the methods of mathematical statistics; parameters of distributions of individual sizes as random variables were calculated. On the basis of values of variation coefficient, the density function of normal distribution (Gaussian distribution) was taken as a model of individual sizes of seeds. Models of two-dimensional distributions of seed sizes as independent random variables were presented. Correlation coefficients between geometric sizes of seeds were calculated. Obtained values of the correlation coefficients indicate that the geometric sizes of seeds should be considered as dependent random variables. Mathematical models of geometric sizes of studied cereal crops' seeds as dependent random variables in the form of density functions of their normal distribution were proposed. By values of the sums of squared deviations as a fitting criterion, it was established that the mathematical models of geometric sizes of seeds as dependent random variables in the form of density functions of their normal distribution provide better data approximation than the mathematical models of geometric sizes of some cereal crops' seeds as independent random variables.
\end{abstract}

Keywords: wheat; seeds; geometric parameters; simulation; the random value; the distribution function

Cereal crops' seeds as a biological material are very variable. Geometric sizes of seeds of different crops need to be known in order to provide an efficient separation process, as well as to adequately design the machinery and equipment for transport, storage and further processing of grain. Generally, only two geometric sizes of the seeds are distinguished length and width (since the thickness and width of seeds are considered to be the same). Furthermore, literature provides information merely on the limits of variation of individual geometric sizes of certain crops' seeds. For all intents and purposes, it is important to specify the probability distribution laws of all the three principal dimensions of seeds as random variables, taking into account the relationships between individual sizes additionally.

Researchers from many countries studied the geometric sizes of seeds of different crops (Evchenko, 2016; Karaj and Muëller, 2010; Kovalyshyn et al., 2015; Müller et al., 2015; Niveditha et al., 2013). Multiple scientific papers (Karimi et al., 2009; Milani et al., 2007; Sanchez-Mendoza et al., 2008; Sokolovskyi et al., 2012; Tabatabaeefar, 2003; Zewdu and Solomon, 2007) have dealt with the effect of relative moisture on the dimensions of seeds of different crops. Particularly, many authors (Gursoy and Guzel, 2010; Karimi, 2011; Mansouri et al., 2015; Mirzabe et al., 2013; Tabatabaeefar, 2003) examined the geometric sizes of seeds as random variables. As a result of the statistical processing of measurements of geometric sizes of winter wheat seeds, the laws of distribution of length, width and thickness of seeds of particular varieties were established (Sokolovskyi et al., 2012). Two-dimensional Weibull distribution was used for description of the geometric sizes of raisins, assuming that individual geometric sizes are independent random variables (Karimi, 2011). Obtaining two-dimensional distributions of geometric sizes of seeds is essential for ensuring the proper quality of separation processes (Kuzminskyi et al., 2014).

The aim of the study is to establish the relationship between individual geometric sizes of seeds of cereal crops and to obtain mathematical models of their distribution based on the results of experimental studies.

\section{Material and methods}

Geometric dimensions of wheat seeds were determined by measuring the length $(I)$, width $(b)$ and thickness $(h)$, as shown in Fig. 1.

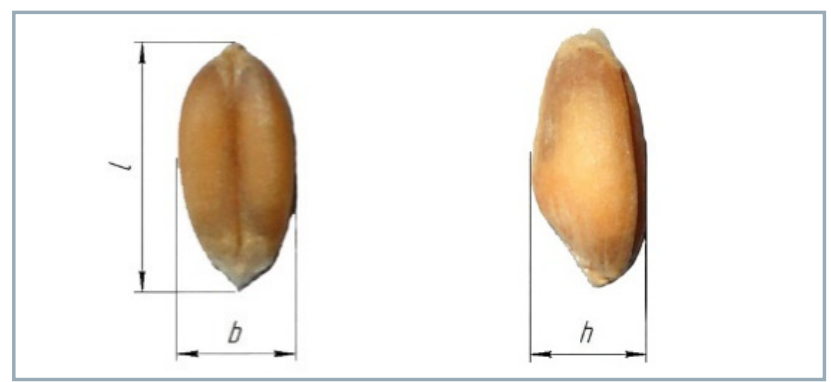

Fig. 1 Dimensions of wheat seed

$l$ - seed length, $b$ - seed width, $h$ - seed thickness 
Dimensions of 100 randomly selected wheat seeds of the Smuglyanka variety (relative moisture 14.4\%), rye seeds of the Puhovchanka variety (relative moisture $13.4 \%$ ) and barley seeds of the Pejas variety (relative moisture 12.7\%) were measured using a microscope Sigeta Forward (Fig. 2) with magnification from 10 to 500 times.

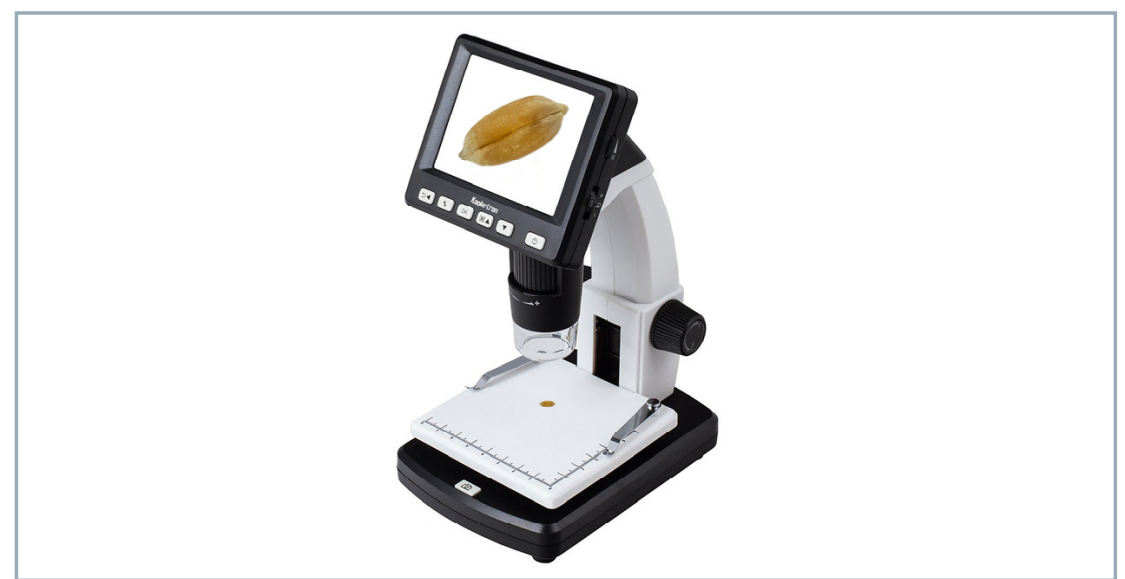

Fig. 2 Microscope Sigeta Forward

Density functions of the normal distribution of individual dimensions as random variables are as follows:

$$
f(x)=\frac{1}{\sigma[x] \sqrt{2 \pi}} e^{-\left[\frac{(x-M[x])^{2}}{2 \sigma[x]^{2}}\right]}
$$

and the integral function of their distribution is:

$$
F(x)=\frac{1}{\sigma[x] \sqrt{2 \pi}} \int_{-\infty}^{x} e^{-\left[\frac{(x-M[x])^{2}}{2 \sigma[x]^{2}}\right]} d x
$$

where:

$M[x]$ - theoretical average, $\mathrm{mm}$

$\sigma[x]-$ mean square deviation, $\mathrm{mm}$

$x \quad$ - random variable (length, width or thickness of the seed), $\mathrm{mm}$

For instance, considering the length and width of the seed as independent normally distributed random variables, taking into account the type of differential function (1), the model of their two-dimensional distribution is obtained as follows:

$$
\begin{gathered}
f(I, b)=f(I) f(b) \\
f(I, b)=\frac{1}{2 \pi \sigma[I] \sigma[b]} e^{-0,5\left[\frac{(I-M[I])^{2}}{\sigma[I]^{2}}+\frac{(b-M[b])^{2}}{\sigma[b]^{2}}\right]}
\end{gathered}
$$

Given the correlation coefficient $r_{l b}$ between the length $/$ and width $b$ of the seed, the two-dimensional normal distribution model will have the form:

$$
f(I, b)=\frac{1}{2 \pi \sigma[l] \sigma[b] \sqrt{1-r_{l b}^{2}}} e^{\frac{-1}{2\left(1-r_{l b}^{2}\right)}\left[\frac{(I-M[I])^{2}}{\sigma[I]^{2}}+\frac{(b-M[b])^{2}}{\sigma[b]^{2}}-2 r_{l b} \frac{I-M[I]}{\sigma[l]} \cdot \frac{b-M[b]}{\sigma[b]}\right]}
$$

where:

$M[I], M[b]$-theoretical average of the length and width of seeds, respectively, $\mathrm{mm}$ $\sigma[l], \sigma[b]-$ mean square deviation of the length and width of seeds, respectively, $\mathrm{mm}$

$r_{l b} \quad$ - the value of the correlation coefficient between / and $b$

Correlation coefficient was calculated by means of the following formula:

$r_{x y}=\frac{\sum(x-M[x])(y-M[y])}{\sqrt{\sum(x-M[x])^{2} \sum(y-M[y])^{2}}}$

where:

$x, y$ - geometric dimensions (length, width or height), $\mathrm{mm}$

$M[x], M[y]$ - theoretical average of the sizes $x$ and $y$, respectively, $\mathrm{mm}$

The criterion of the sum of squared deviations (SSD) is used for comparison of results from the approximation of experimental data in terms of measurement of seed sizes by twodimensional distributions of their geometric sizes, both independent and dependent random variables. The criterion of fitting was calculated by means of the following formula:

$$
S S D=\sum_{i=1}^{k_{i}}\left(\sum_{j=1}^{k_{j}}\left(m_{i, j}-m_{\mathrm{T} i, j}\right)^{2}\right)
$$

where:

$i, j \quad$ - sequence count of intervals of geometric sizes of seeds, as random variables

$k_{i}, k_{j}$ - number of intervals of individual geometric sizes of seeds

$m_{i, j}, m_{T i, j}$ - number of data in individual intervals of geometric sizes of seeds, obtained respectively as the results from measurements and on the basis of the calculated results using the theoretical models in the form of twodimensional distributions of random variables

\section{Results and discussion}

Parameters of the distribution of geometric sizes of wheat seeds of the Smuglyanka variety are given in Table 1. Geometric sizes of wheat seeds of the Smuglyanka variety are very similar to the sizes obtained by other 
Table 1 Parameters of the distribution of geometric sizes of the Smuglyanka variety wheat seeds

\begin{tabular}{|l||c|c|c|}
\hline Geometric sizes & Mean value $\mathbf{( m m})$ & Range of measurement results $\mathbf{( m m})$ & Mean square deviation $(\mathbf{m m})$ \\
\hline Length $\mathbf{( m m})$ & 6.755 & $5.9-7.5$ & 0.13 \\
\hline Width $\boldsymbol{b}(\mathbf{m m})$ & 3.255 & $2.39-3.94$ & 0.097 \\
\hline Thickness $\boldsymbol{h}(\mathbf{m m})$ & 2.845 & $2.28-3.47$ & 0.0697 \\
\hline
\end{tabular}

researchers for seeds of other varieties of wheat (Evchenko, 2016; Gursoy and Guzel, 2010; Karimi et al., 2009; Tabatabaeefar, 2003).

On the basis of values of variation coefficient of individual geometric sizes of seed, a hypothesis about their normal distribution (Gaussian distribution) was proposed.

Differential functions of the normal distribution of length $(I)$, width $(b)$ and thickness $(h)$ for wheat seeds of the Smuglyanka variety are as follows:

$$
\begin{gathered}
f(I)=\frac{1}{0.13 \sqrt{2 \pi}} e^{-\left[\frac{(I-6.775)^{2}}{2 \cdot 0.13^{2}}\right]} \\
f(b)=\frac{1}{0.097 \sqrt{2 \pi}} e^{-\left[\frac{(b-3.255)^{2}}{2 \cdot 0.097^{2}}\right]} \\
f(h)=\frac{1}{0.0697 \sqrt{2 \pi}} e^{-\left[\frac{(b-2.845)^{2}}{2 \cdot 0.0697^{2}}\right]}
\end{gathered}
$$

Fig. 3 shows histograms and density functions for the length (l), width $(b)$ and thickness $(h)$ of wheat seeds.

Parameters of the normal distribution of the geometric sizes (length, width and thickness) of the Puhovchanka variety rye seeds and of the Peyas variety barley seeds are given in Table 2. Geometric sizes of the Peyas variety barley seeds are also very similar to the parameters obtained by other researchers for other varieties of barley seeds (Evchenko, 2016; Gursoy and Guzel, 2010).
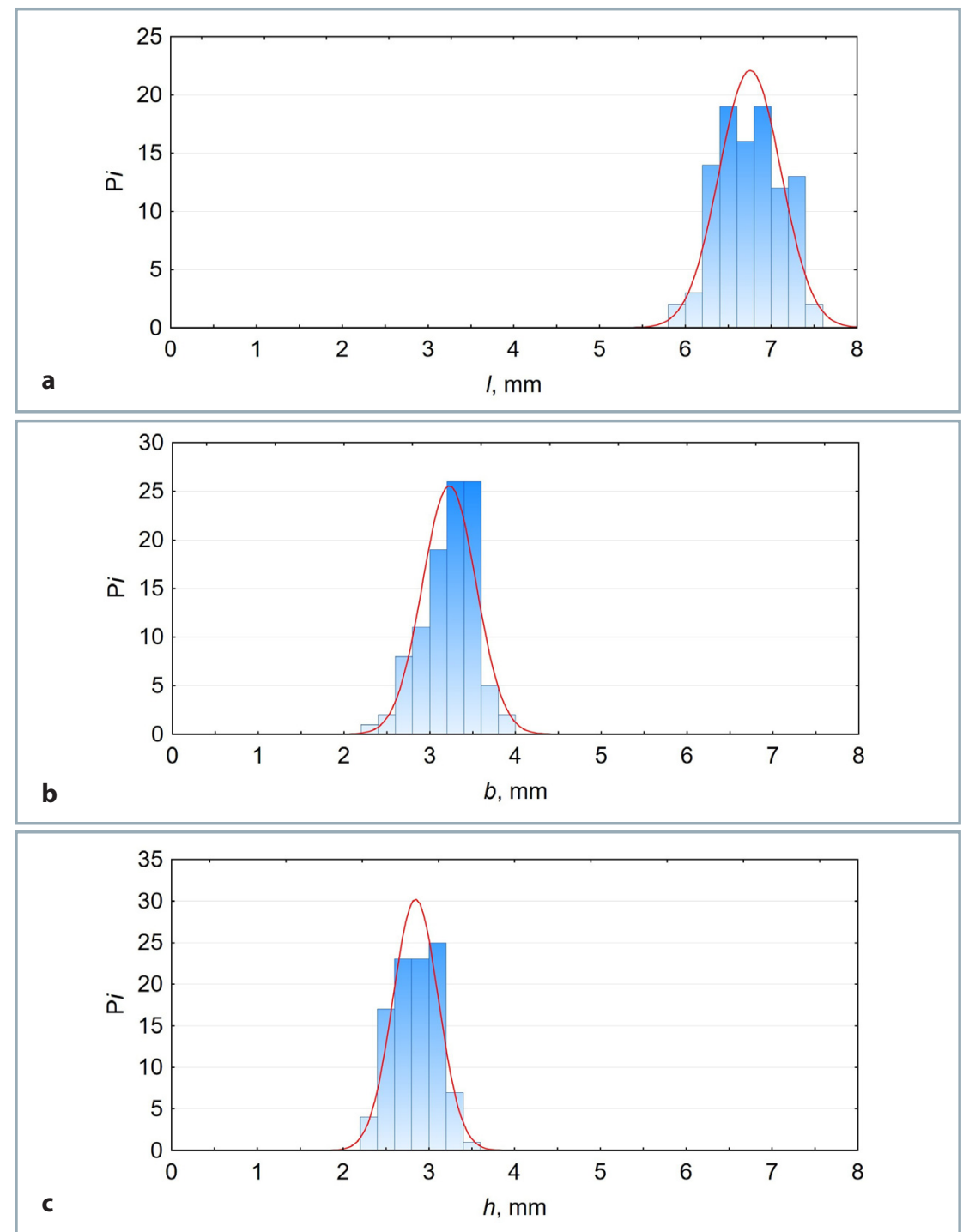

Fig. 3 Histograms and density functions of probability distribution of geometric sizes of the Smuglyanka variety wheat seeds (relative moisture 14.4\%)

\begin{tabular}{|c|c|c|c|}
\hline \multirow{2}{*}{$\begin{array}{l}\text { Culture, variety } \\
\text { (relative moisture) }\end{array}$} & \multirow[t]{2}{*}{ Dimensions of seed } & \multicolumn{2}{|c|}{ Parameters } \\
\hline & & $M[x](\mathrm{mm})$ & $\sigma[x](\mathbf{m m})$ \\
\hline \multirow{3}{*}{$\begin{array}{l}\text { Rye seeds } \\
\text { of the Puhovchanka variety (13.4\%) }\end{array}$} & length / (mm) & 8.425 & 0.436 \\
\hline & width $b(\mathrm{~mm})$ & 2.915 & 0.061 \\
\hline & thickness $h(\mathrm{~mm})$ & 2.88 & 0.0399 \\
\hline \multirow{3}{*}{$\begin{array}{l}\text { Barley seeds } \\
\text { of the Peyas variety }(12.7 \%)\end{array}$} & length / (mm) & 8.63 & 0.411 \\
\hline & width $b(\mathrm{~mm})$ & 3.87 & 0.0889 \\
\hline & thickness $h(\mathrm{~mm})$ & 3.18 & 0.0587 \\
\hline
\end{tabular}
$\mathrm{a}$ - length $(h), \mathrm{b}$ - width $(b), \mathrm{c}$ - thickness $(h)$

Table 2 Parameters of normal distribution of geometric sizes of wheat seeds 
Table 3 Values of the correlation coefficients between the individual dimensions of the studied crops' seeds

\begin{tabular}{|c|c|c|c|}
\hline \multirow[b]{2}{*}{ Culture, variety } & \multicolumn{3}{|c|}{ Correlation coefficients: } \\
\hline & $\begin{array}{l}\text { between length } \\
\text { and width }\end{array}$ & $\begin{array}{l}\text { between width } \\
\text { and thickness }\end{array}$ & $\begin{array}{c}\text { between length } \\
\text { and thickness }\end{array}$ \\
\hline Rye seeds of the Puhovchanka variety & 0.422 & 0.237 & 0.217 \\
\hline Barley seeds of the Peyas variety & 0.403 & 0.695 & 0.277 \\
\hline Wheat seeds of the Smuglyanka variety & 0.266 & 0.745 & 0.475 \\
\hline
\end{tabular}

Values of the correlation coefficients between the dimensions of seeds of the studied crops are given in Table 3.

Since the values of the correlation coefficients between the individual dimensions of seeds are $r>0.4$, there is an indication of a steady correlation between these sizes. According to different data (Evchenko, 2016), the highest correlation coefficient $(r>0.55)$ was observed between the thickness and width of the wheat seeds, and the lowest correlation was observed between length and width of the wheat seeds $(r<0.34)$.

Consequently, such a rigid correlation must be taken into account in the model of the two-dimensional normal distribution of seed sizes. Thus, the twodimensional normal distribution models of geometric dimensions of wheat seeds of the Smuglyanka variety are as follows:

$f(I, b)=\frac{1}{2 \pi 0.13 \cdot 0.097 \sqrt{1-0.266^{2}}} e^{\frac{-1}{2\left(1-0.266^{2}\right)}\left[\frac{(I-6.775)^{2}}{0.13^{2}}+\frac{(b-3.255)^{2}}{0.097^{2}}-2 \cdot 0.266 \frac{1-6.775}{0.13} \cdot \frac{b-3.255}{0.097}\right]}$

$f(I, h)=\frac{1}{2 \pi 0.13 \cdot 0.07 \sqrt{1-0.745^{2}}} e^{\frac{-1}{2\left(1-0.745^{2}\right)}\left[\frac{(1-6.775)^{2}}{0.13^{2}}+\frac{(h-2.845)^{2}}{0.07^{2}}-2 \cdot 0.745 \frac{I-6.775}{0.13} \cdot \frac{h-2.845}{0.07}\right]}$

$f(b, h)=\frac{1}{2 \pi 0.097 \cdot 0.07 \sqrt{1-0.475^{2}}} e^{\frac{-1}{2\left(1-0.475^{2}\right)}\left[\frac{(b-3.255)^{2}}{0.097^{2}}+\frac{(h-2.845)^{2}}{0.07^{2}}-2 \cdot 0.475 \frac{b-3.255}{0.097} \cdot \frac{h-2.845}{0.07}\right]}$

Models of two-dimensional normal distribution of the Smuglyanka variety wheat seed geometric sizes as dependent random variables are presented in Fig. 4.
Lines of levels of two-dimensional distribution of length $/$ and width $b$ of the Smuglyanka variety wheat seeds as dependent random variables are shown in Fig. 5.

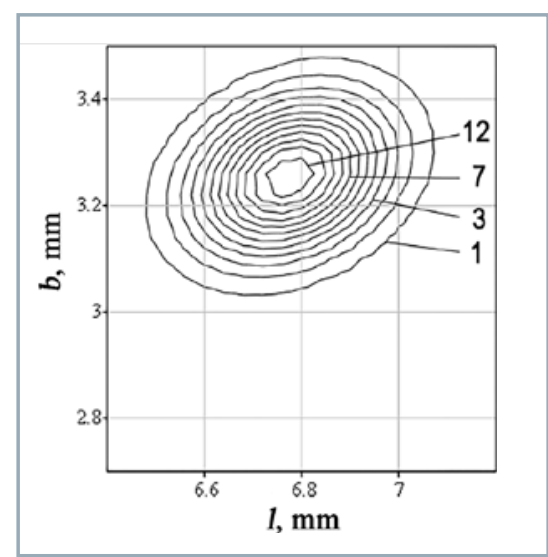

Fig. 5 Lines of levels of density functions of two-dimensional probability distribution of length $I$ and width $b$ of the Smuglyanka variety wheat seeds as dependent random variables

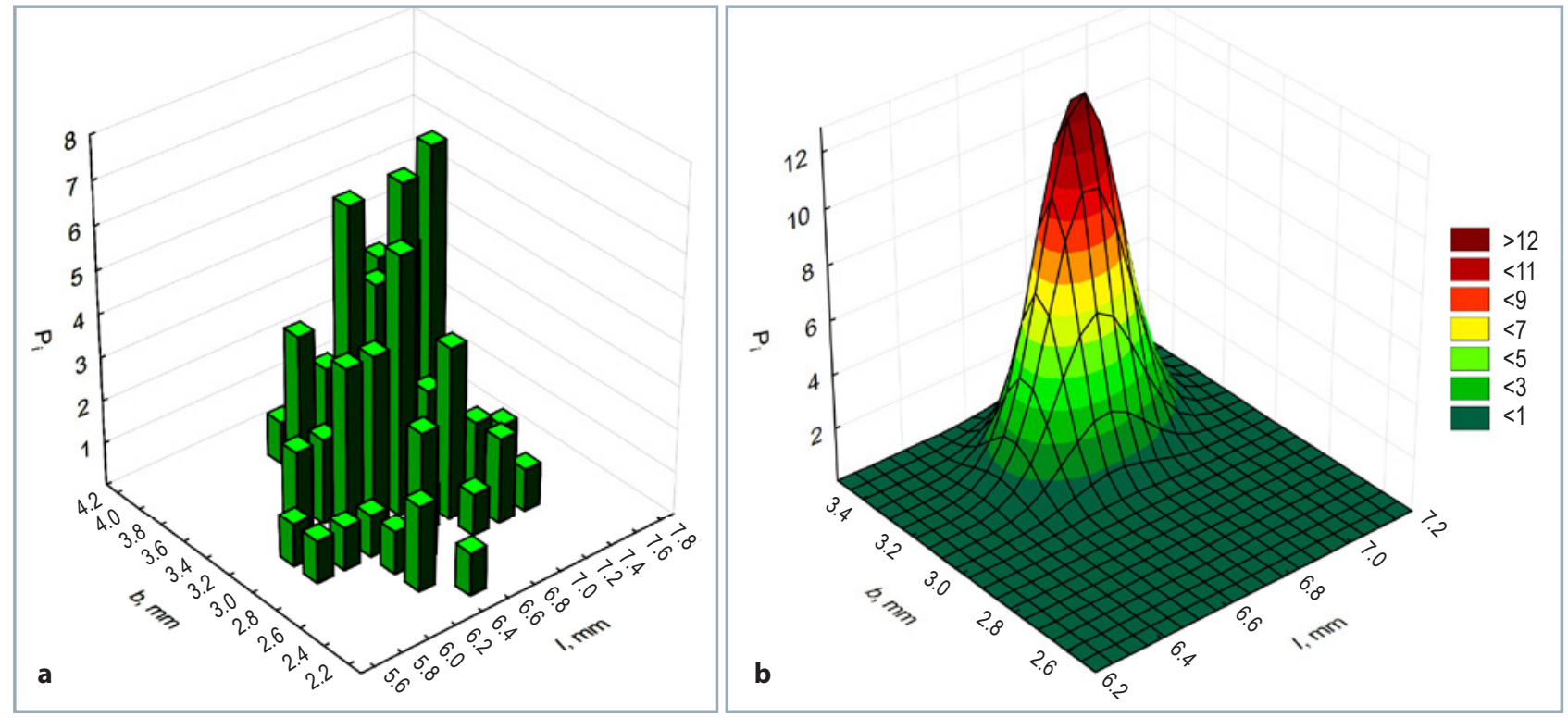

Fig. 4 Histogram (a) and density function of probability distribution (b) of the Smuglyanka variety wheat seed geometric sizes as dependent random variables $-f(I, b)$ 
Values of SSD between experimental and theoretical frequency of occurrences in approximation of geometric sizes distributions

\begin{tabular}{|l||c|c|c|c|c|c|}
\hline \multicolumn{1}{|c||}{ Culture, variety } & \multicolumn{5}{c|}{$\begin{array}{c}\text { Sum of squared deviations (SSD) } \\
\text { of approximation of geometric sizes distributions }\end{array}$} \\
\cline { 2 - 7 } & \multicolumn{2}{|c|}{ length and width } & width and thickness & \multicolumn{2}{|c|}{ length and thickness } \\
\hline \hline Rye seeds of the Puhovchanka variety & $\mathbf{1}$ & $\mathbf{2}$ & $\mathbf{1}$ & $\mathbf{2}$ & $\mathbf{1}$ & $\mathbf{2}$ \\
\hline Barley seeds of the Peyas variety & 1145.73 & 685.02 & 3925.61 & 2834.36 & 2039.99 & 1446.35 \\
\hline Wheat seeds of the Smuglyanka variety & 2917.83 & 2379.01 & 3670.04 & 3193.26 & 2498.14 & 2158.95 \\
\hline
\end{tabular}

1 - as independent random variables; 2 - as dependent random variables

Values of SSD between experimental and theoretical frequency of occurrences, which has been calculated according to two-dimensional distributions of geometric sizes of the studied seeds, respectively, both independent and dependent random variables are given in Table 4.

Obtained SSD values indicate that mathematical models of the geometric sizes of the studied cereal crops' seeds in the form of density functions of their two-dimensional normal distribution as dependent random variables provide a higher accuracy of approaching empirical data.

\section{Conclusion}

In order to take into account the considerable variability of the cereal crops' seed size, these sizes should be considered as random variables. Using two-dimensional distribution of geometric dimensions of seeds as random variables for calculation of separation processes will improve their quality. Values of the correlation coefficients between the individual geometric sizes of the studied crops' seeds indicate a stable correlation between them. Mathematical models of the studied cereal crops' seed geometric sizes as density functions of their normal distribution as dependent random variables provide a higher accuracy of approximation and, thus, the models can be recommended for utilization in the calculation and design of technological equipment for the processing and storage of grain.

\section{References}

EVCHENKO, A.V. 2016. Analysis of physical and mechanical properties of grain crops seeds. In Bulletin of KrasGAU, no. 8, pp. 144-149. ISSN 1819-4036 (in Russian: Анализ физикомеханических свойств семян зерновых культур).

GURSOY, S. - GUZEL, E. 2010. Determination of physical properties of some agricultural grains. In Research Journal of Applied Sciences, Engineering and Technology, vol. 2, no. 5, pp. 492-498.

KARAJ, S. - MUËLLER, J. 2010. Determination of physical, mechanical and chemical properties of seeds and kernels of Jatropha curcas L. In Industrial Crops and Products, vol. 32, no. 2, pp. 129-138.

KARIMI, M. - KHEIRALIPOUR, K. - TABATABAEEFAR, A. - KHOUBAKHT, G. M. - NADERI, M. - HEIDARBEIGI, K. 2009. The effect of moisture content on physical properties of wheat. In Pakistan Journal of Nutrition, vol. 8, no. 1, pp. 90-95.

KARIMI, N. - ARABHOSSEINI, A. - KIANMEHR, M. H. - KHAZAEI, J. 2011. Modelling of raisin berries by some physical and statistical characteristics. In International Agrophysics, vol. 25, no. 2, pp. 141-147.
KOVALYSHYN, S. - DADAK, V. - KONYK, S. 2015. Intensification of the process of preparing small seed crop mixtures. In Acta Technologica Agriculture, vol. 18, no. 4, pp. 108-112.

KUZMINSKYI, R. - SOKOLOVSKYI, O. - SHEREMETA, R. 2014. Modeling geometrical parameters of seed crops using multidimensional distributions. In The Role of Science in Improving the Technological Level and Efficiency of the Agro Industrial Complex of Ukraine : Theses Int. Science-Practice Conf., Ternopil, pp. 91-94. ISBN 978-617-692-186-8 (in Ukrainian: Моделювання геометричних параметрів насінин сільськогосподарських культур з використанням багатовимірних розподілів).

MANSOURI, A. - MIRZABE, A. H. - RAUFI, A. 2015. Physical properties and mathematical modeling of melon (Cucumis melo L.) seeds and kernels. In Journal of the Saudi Society of Agricultural Sciences, vol. 16, no. 3, pp. 218-226.

MILANI, E. - SEYED, M. - RAZAVI, A. - KOOCHEKI, A. - NIKZADEH, V. - VAHEDI, N. - MOEIN FARD, M. - GHOLAMHOSSEIN POUR, A. 2007. Moisture dependent physical properties of cucurbit seeds. In International Agrophysics, vol. 21, no. 2, pp. 157-168.

MIRZABE, A. H. - KHAZAEI, J. - CHEGINI, G. R. - GHOLAMI, O. 2013. Some physical properties of almond nut and kernel and modeling dimensional properties. In Agricultural Engineering International: CIGR Journal, vol. 15, no. 2, pp. 256-265.

MÜLLER, M. - HORNÍČKOVÁ, Š. - HRABĔ, P. - MAŘíK, J. 2015. Analysis of physical, mechanical and chemical properties of seeds and kernels of Jatropha curcas. In Research in Agricultural Engineering, vol. 61, no. 3, pp. 99-105.

NIVEDITHA, V. R. - SRIDHAR, K. R. - BALASUBRAMANIAN, D. 2013. Physical and mechanical properties of seeds and kernels of Canavalia of coastal sand dunes. In International Food Research Journal, vol. 20, no. 4, pp. 1547-1554.

SANCHEZ-MENDOZA, J. - DOMINGUEZ-LOPEZ, A. - NAVARROGALINDO, S. - LOPEZ-SANDOVAL, J. A. 2008. Some physical properties of Roselle (Hibiscus sabdariffa L.) seeds as a function of moisture content. In Journal of Food Engineering, vol. 87, 2008, pp. 391-397.

SOKOLOVSKYI, O. - KUZMINSKYI, R. - SHEREMETA, R. 2012. Effect of relative humidity on the geometrical parameters of the seeds of wheat and rye. In Motrol, vol. 14, pp. 65-70.

TABATABAEEFAR, A. 2003. Moisture-dependent physical properties of wheat. In International Agrophysics, vol. 17, pp. 207-211.

ZEWDU, A. D. - SOLOMON, W. K. 2007. Moisture-dependent physical properties of tef seed. In Biosystems Engineering, vol. 96, no. 1, pp. 57-63. 